\title{
Study on the Pictorial Design of Five-color Porcelain "Three Young Men Battling Against Lv Bu" in Kangxi Regime
}

\author{
Xiaomeng $\mathrm{Chi}^{1, *}$ \\ ${ }^{1}$ Jingdezhen Ceramic Institute, Jingdezhen, Jiangxi 333403, China \\ *Corresponding author. Email:2027594892@qq.com
}

\begin{abstract}
Five-color porcelain in Kangxi Regime is the abbreviation for five-color porcelain of the Kangxi period in Qing Dynasty, is rich in colors and patterns, and has varied decorative effects. The story of three brothers Liu Bei, Guan Yu and Zhang Fei, who fought against Lv Bu in a bloody battle on the battleground in Hulaoguan is an exciting storyline from the classic Chinese novel "Romance of the Three Kingdoms". Because of its popular and exciting wonderful story, it is widely spread by people and has spawned many types of artistic expression. This study focuses on the five-color porcelain in Kangxi Regime 'Three Young Men Battling Against Lv Bu', analyzes the design elements of the five-color porcelain in Kangxi Regime 'Three Young Men Battling Against $\mathrm{Lv} \mathrm{Bu}^{\prime}$ in conjunction with the illustrations of the woodblock 'Three Young Men Battling Against Lv Bu' in Ming and Qing Dynasties, and summarizes its pictorial characteristics and design rules, so as to explore the cultural connotations and practical significance it carries.
\end{abstract}

Keywords: Five-color porcelain in Kangxi Regime, 'Three Young Men Battling Against Lv Bu', Pictorial design.

\section{INTRODUCTION}

In the Qing Dynasty, the art of overglaze painting in Jingdezhen flourished, and the fivecolor porcelain reached the peak of creation in the Kangxi Regime. The five-color porcelain in Kangxi Regime, also known as Kangxi ancient color, refers to the overglazed porcelain in Kangxi Regime, which is painted in red, green, blue, yellow, black and other colors. Its lines are strong and powerful, the colors are rich and colorful, the patterns are diverse, and the picture is honest and sincere, so it is also called "hard color". The picture "Three Young Men Battling Against Lv Bu' is a colorful decorative picture of Kangxi Regime. Its rich and fierce battle plot is popular among people and is often painted on porcelain as a decorative picture. Through the systematic analysis of the characters, scene elements and colors in the pictures, this study summarizes the design law of the five-color porcelain 'Three Young Men Battling Against Lv $\mathrm{Bu}^{\prime}$ in Kangxi Regime, in order to enrich the pictorial design research of the five-color porcelain in Kangxi Regime and provide some reference for the pictorial design of modern decorative porcelain art.

\section{THE ORIGIN AND DEVELOPMENT OF THE PICTURE OF 'THREE YOUNG MEN BATTLING AGAINST LV BU'}

\subsection{The Origin of 'Three Young Men Battling Against Lv Bu'}

During the Ming and Qing Dynasties, the society was stable, the economy was prosperous, the woodblock printing technique was further developed, the citizen culture was prosperous, and a large number of novels were published. As a classic literary novel in China, the "Romance of the Three Kingdoms" is deeply loved and advocated by people. A variety of illustrated versions of the "Romance of the Three Kingdoms" have been published, laying a foundation for the establishment 
of the basic program of illustrated pictures on the theme of "the Three Kingdoms".[3]

The plot 'Three Young Men Battling Against Lv $\mathrm{Bu}$ ' originated from a wonderful story in the fifth chapter of the Chinese classical literary novel "Romance of the Three Kingdoms", in which Cao Cao united with the princes to attack Dong Zhuo. After $\mathrm{Lv} \mathrm{Bu}$ defeated the generals, Liu Bei, Guan $\mathrm{Yu}$ and Zhang Fei fought with $\mathrm{Lv} \mathrm{Bu}$ to the death at Hulaoguan.[1] Later, the scenes were presented in several illustrated versions of the "Romance of the Three Kingdoms". Although the details and artistic styles were different, the basic procedures were roughly the same, which enriched the ceramic decoration theme of "knife-horse-man" in the Ming and Qing Dynasties.

\subsection{Artistic Expression Types of 'Three Young Men Battling Against Lv Bu'}

In the long history of Chinese art, people enjoy the performance of theme 'Three Young Men Battling Against Lv Bu'. Its artistic expression types are also rich and diverse, such as New Year pictures, silk weaving, sculpture, shadow play, drama, ceramics and carved lacquer. In terms of its artistic expression on ceramics, the five-color porcelain in Kangxi Regime is the most exquisite.

In the picture books of "Emperor Xianzong seeking amusement on the Lantern in the Ming Dynasty"("Figure 1") and "prosperity in Nandu" ("Figure 2"), there were drama scenes depicting the 'Three Young Men Battling Against Lv Bu' in the Ming Dynasty, meticulously depicting the instant scenes of Liu Bei, Guan Yu and Zhang Fei battling against $\mathrm{Lv} \mathrm{Bu}$, reflecting that the drama culture of 'Three Young Men Battling Against $\mathrm{Lv} \mathrm{Bu}^{\prime}$ was widely loved and advocated by the ruling class and the civil class. At the same time, the pictures depicted a wealth of artistic performances and parades, reflecting the real social life and folk culture of the Ming Dynasty, showing high historical, cultural and artistic research value.

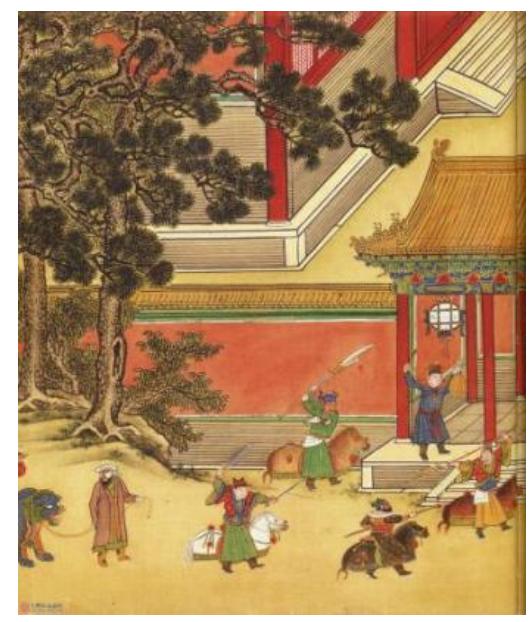

Figure 1 (Ming Dynasty) The painting of Emperor Xianzong seeking amusement on the Lantern (partial), collected by the National Museum of China $(37 \mathrm{~cm} \times 624 \mathrm{~cm})$.

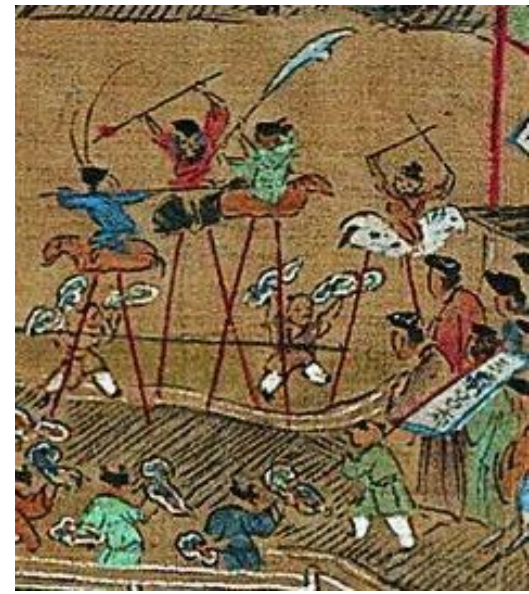

Figure 2 (Ming Dynasty) The scroll of prosperity in Nandu (partial), collected by the National Museum of China $(44 \mathrm{~cm} \times 350 \mathrm{~cm})$.

In addition to the paintings, there are many sculptures, including stone, brick, wood, ivory and bamboo carvings. For example, the relief carving of 'Three Young Men Battling Against Lv Bu' on the Wenfeng Pagoda in Xilai Ancient Town, the brick carving of 'Three Young Men Battling Against Lv $\mathrm{Bu}^{\prime}$ in the Chongming County Museum, the ivory carving of 'Three Young Men Battling Against Lv $\mathrm{Bu}^{\prime}$ from the Qing Dynasty, and the bamboo carving of 'Three Young Men Battling Against Lv $\mathrm{Bu}^{\prime}$ in the Qianlong Regime of the Qing Dynasty performed the art based on the theme of 'Three Young Men Battling Against $\mathrm{Lv} \mathrm{Bu}^{\prime}$. The four famous generals of the Three Kingdoms were meticulously carved in terms of their demeanou, dynamics, costumes and weapons, all of which 
were portrayed and distinguished exquisitely. The characters' personalities were portrayed vividly.

\section{THE INFLUENCE OF WOODBLOCKS ON THE FIVE- COLOR PORCELAIN 'THREE YOUNG MEN BATTLING AGAINST LV BU' IN KANGXI REGIME}

The five-color porcelain in Kangxi Regime is an outstanding example of the porcelain art in the Qing Dynasty, representing the highest level of the art. The colours are vivid and bright, the subjects are rich and varied, and the designs are exquisitely drawn, with a warm and calm artistic style. During the Ming and Qing Dynasties, woodcut pictures developed and matured relatively quickly, and a large number of illustrations of opera and novel appeared, with "more than 30 types of engravings in the Ming Dynasty alone, and up to 70 types $^{1}$ [5] in the Qing Dynasty". The woodblocks of this period were rustic in style, with strong, hard lines and vivid figures. The prosperity of printmaking drove the development of ceramic art and provided many useful references for the development of ceramic art. In the illustration of 'Three Young Men Battling Against Lv Bu at Hulaoguan' in Da Kui Tang Collection ("Figure 3") and the 'Three Young Men Battling Against Lv Bu' of blue and white porcelain "Romance of the Three Kingdoms" in Chongzhen Regime of Ming Dynasty from the Musée Guimet Collection ("Figure 4"), it can be seen that there are many similarities between the two. The ceramic pictures draw on the illustration of the woodblock 'Three Young Men Battling Against Lv Bu' in terms of figures, dynamic features, composition and decorative elements, and form a distinctive artistic style in combination with its own artistic characteristics.
1. Zhu Xiangming. A study on the relationship between the text and illustrations of "Three Kingdoms" in the Ming and Qing dynasties [D]. Nanjing University. 2014.61.

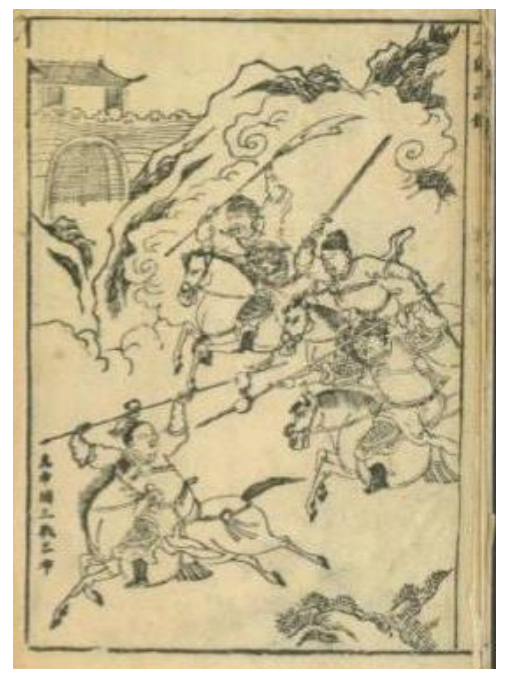

Figure 3 'Three Young Men Battling Against Lv Bu at Hulaoguan', Statue of the Three Kingdoms. (Da Kui Tang Collection).

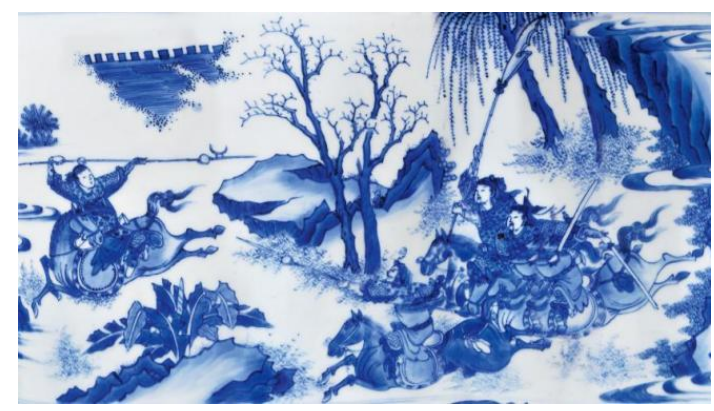

Figure 4 A vase 'Three Young Men Battling Against Lv Bu', blue and white porcelain "Romance of the Three Kingdoms" in Chongzhen Regime of Ming Dynasty (partial), collected in the Musée Guimet, France.

\section{THE PICTORIAL DESIGN OF THE FIVE-COLOR 'THREE YOUNG MEN BATTLING LU BU' IN KANGXI REGIME}

\subsection{The Character Design of the Five- Color Porcelain 'Three Young Men Battling Against Lv Bu' in Kangxi Regime}

In the five-color porcelain 'Three Young Men Battling Against Lv Bu' in Kangxi Regime, the ceramic artist used the decorative form of enamelling to create a detailed portrayal of the moment when the three brothers Liu Bei, Guan Yu and Zhang Fei fight $\mathrm{Lv} \mathrm{Bu}$. Through different dynamic characteristics, facial expression, clothing characteristics, weapons and other elements, the 
different personality characteristics and psychological activities of the characters were reflected, and it reproduced the wonderful story scene of 'Three Young Men Battling Against Lv $\mathrm{Bu}^{\prime}$, and retained the style characteristics of Chen Laolian's painting in the late Ming and early Qing Dynasties.[4]

"He is wearing a purple and gold crown, a red brocade robe with hundred flowers, an armour with beast's face, a belt with lion, a bow and arrows, and an halberd, and a red hare. Indeed, "Lu $\mathrm{Bu}$ is prominent among men and Red Hare is outstanding among horses!" ${ }^{2}$ [2] According to this sentence, it can be seen that $\mathrm{Lv} \mathrm{Bu}$ was a dashing and valiant warrior. It can be seen from the figures below ("Figure 5", "Figure 6", and "Figure 7") that the purple gold crown on Lv Bu's head and hair is outlined with alum red, and then filled with gold powder; the face is exquisitely painted. The eyes, eyebrows and hair temples are painted with red clear, and the other parts are outlined with alum red to reflect the natural skin color. The robe with hundred flowers is hung on the body, outlined in lines, and then filled with water; the armor with animal face on the shoulder shows the hard texture by drawing the armor in the scale pattern, "human pattern", straight line and point. There are exquisite belts with lion patterns around the waist, which are expressed in the form of circles and squares, outlined with red clear and then filled with water material. Holding halberd in his hand, $\mathrm{Lv} \mathrm{Bu}$ rode on Red Hare and fought and walked. After turning his side, he fought against the three brothers Liu Bei, Guan Yu and Zhang Fei, vividly depicting Lv Bu's bravery, majestic and dignified image of a military general.

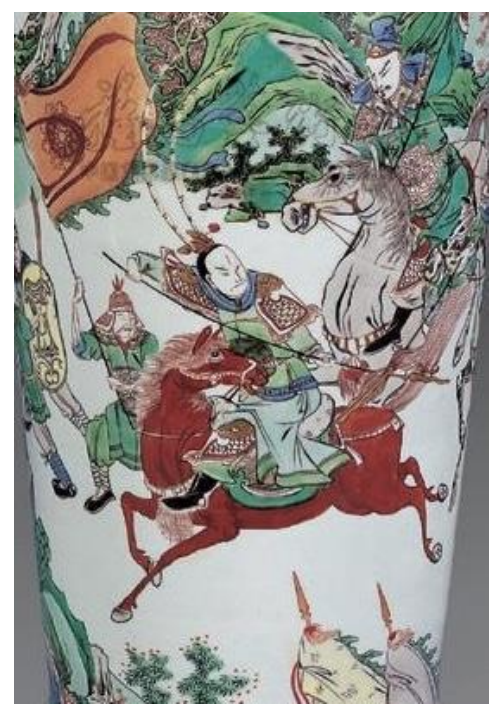

Figure 5 (Qing Dynasty) A five-color vase 'Three Young Men Battling Against Lv Bu' in Kangxi Regime (partial), Guardian, Spring 2003.

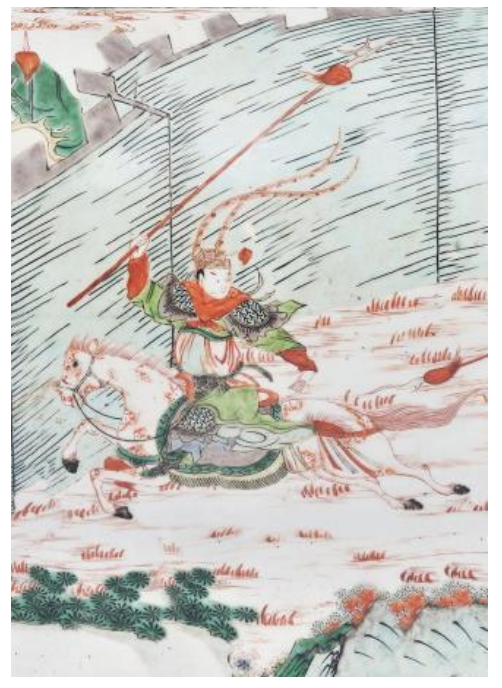

Figure 6 (Qing Dynasty) A five-color hat-covered jar 'Three Young Men Battling Against Lv Bu' in Kangxi Regime (partial), 45th, Fourth Season, Guardian, 2016.
2. In the first year of Jiajing regime of Ming Dynasty (1522), the Romance of The Three Kingdoms, vol. 1, "three battles against Lv Bu at Hulaoguan", photocopy of People's Literature Publishing House, 1975. 


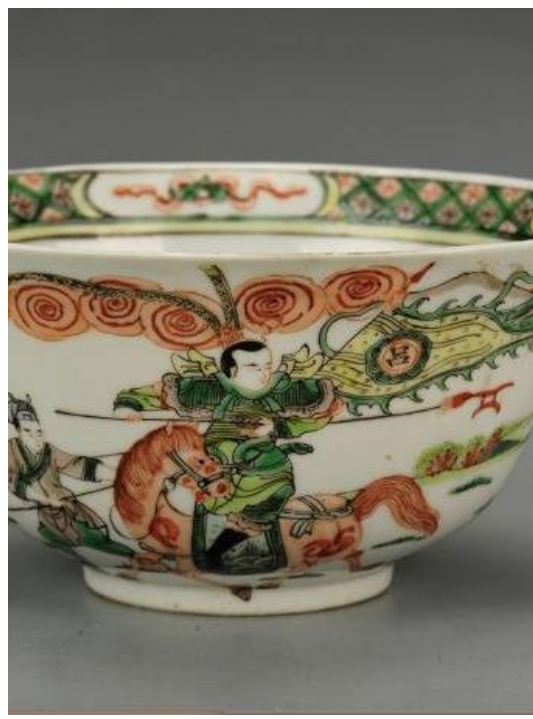

Figure 7 (Qing Dynasty) A five-color grain bowl 'Three Young Men Battling Against Lv Bu' in Kangxi Regime (partial), collected in Zhenjiang Museum.

Guan $\mathrm{Yu}$, a widely known and a famous general of the Three Kingdoms, has been passed down to this day for his heroic image of righteousness, wisdom and courage. "He is tall (nine feet 3 inches), with a beard one foot 8 inches long, a jujubecolored face, vermilion lips, phoenix eyes, recumbent eyebrows, and an imposing appearance." ${ }^{3}$ [2] According to this sentence, a depiction of Guan $\mathrm{Yu}$ from the "Romance of the Three Kingdoms" can be seen. In the following picture, it can be seen that the five-color porcelain Guan Yu in Kangxi Regime is more impressive, with a tall figure, riding on Red Hare and wielding Green Dragon Crescent Blade in the battle; his head is covered with a turban and conical cap, drawn with vermilion material and filled with ancient green; his eyes are phoenix-shaped, his eyebrows are crouching, his facial expression is serious and upright, and hundreds of beards are drawn with black vermilion material, so as to show his bravery; the rest of his features are painted in alum red; he wears a green brocade robe given to him by Liu Bei, filled with ancient green, which is worn but reflects his loyalty to Liu Bei and his brotherly love for him. ("Figure 8, "Figure 9", and "Figure 10")

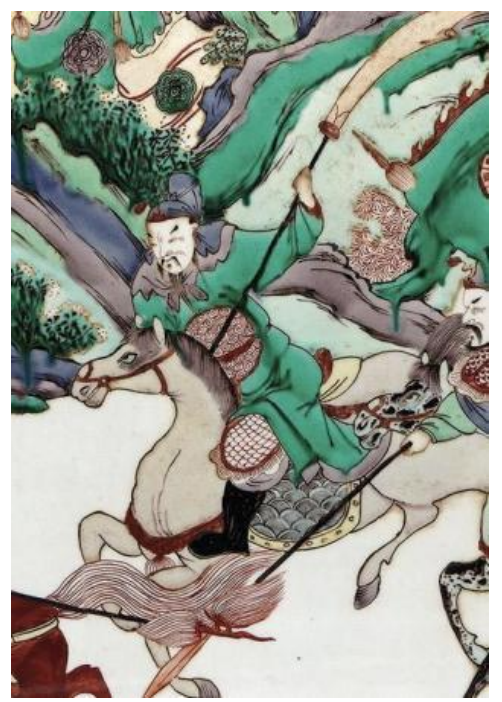

Figure 8 (Qing Dynasty) A five-color handicap 'Three Young Men Battling Against Lv Bu' in Kangxi Regime (partial), Beijing, Spring 2016.

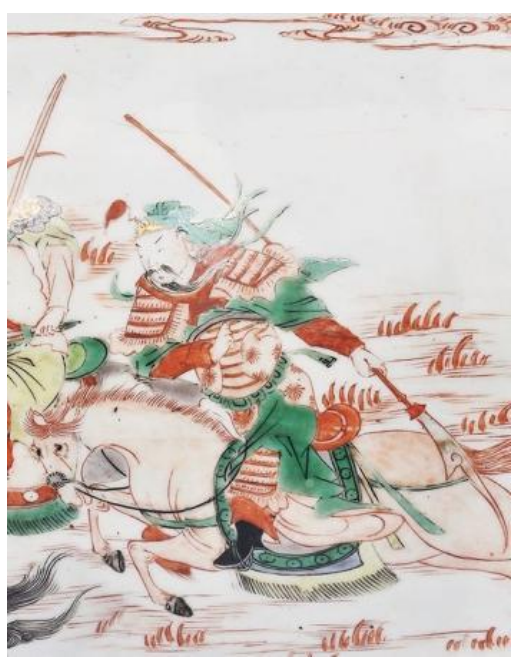

Figure 9 (Qing Dynasty) A five-color hat-covered jar 'Three Young Men Battling Against Lv Bu' in Kangxi Regime (partial), 45th, Fourth Season, Guardian, 2016.

3. In the first year of Jiajing regime of Ming Dynasty (1522), the Romance of The Three Kingdoms, vol. 1, "three battles against Lv Bu at Hulaoguan", photocopy of People's Literature Publishing House, 1975. 


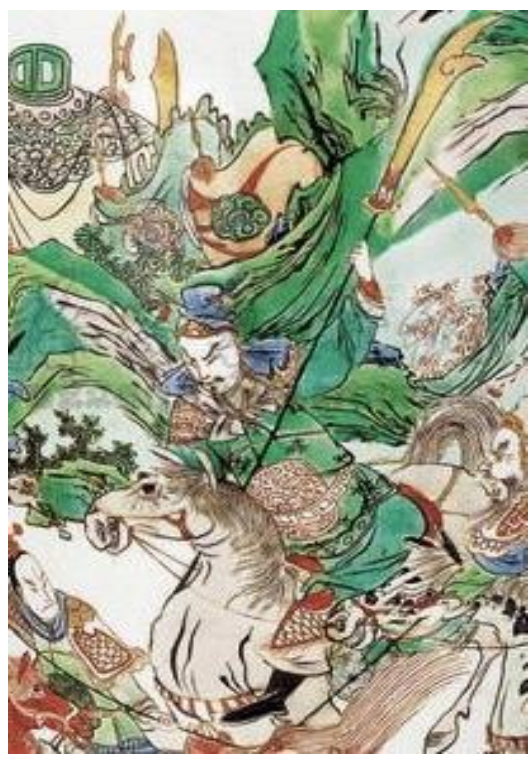

Figure 10

(Qing Dynasty) A five-color vase 'Three Young Men Battling Against Lv Bu' in Kangxi Regime (partial), Guardian, Spring 2003.

Liu Bei is portrayed in the Romance of the Three Kingdoms as a benevolent monarch, described as $\mathrm{He}$ was tall of stature. His ears were long, the lobes touching his shoulders, and his hands hung down below his knees. His eyes were very big and prominent so that he could see backward past his ears. His complexion was as clear as jade, and he had rich red lips. ${ }^{4 "}$ [2] Liu Bei is depicted in five-color porcelain in Kangxi Regime, his clothes are finely drawn, with many folds to show the folds; his body is smaller in size compared with Guan Yu. ("Figure 11", "Figure 12", and "Figure 13")

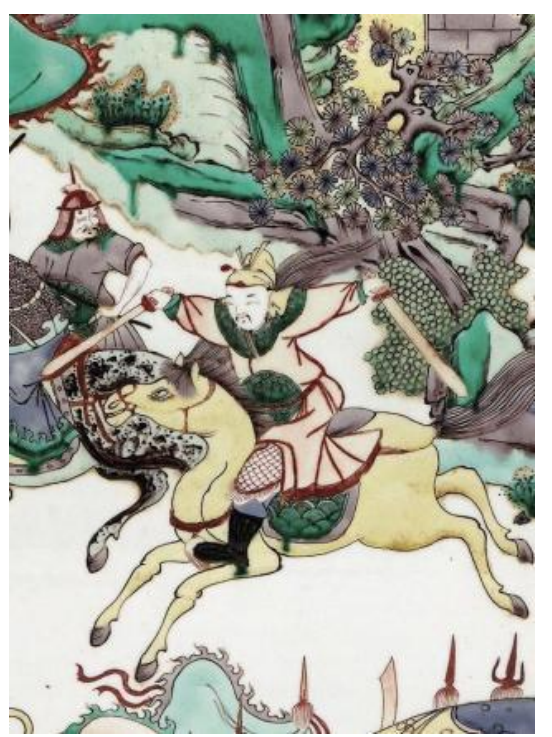

Figure 11

(Qing Dynasty) A five-color handicap 'Three Young Men Battling Against Lv Bu' in Kangxi Regime (partial), Beijing, Spring 2016.

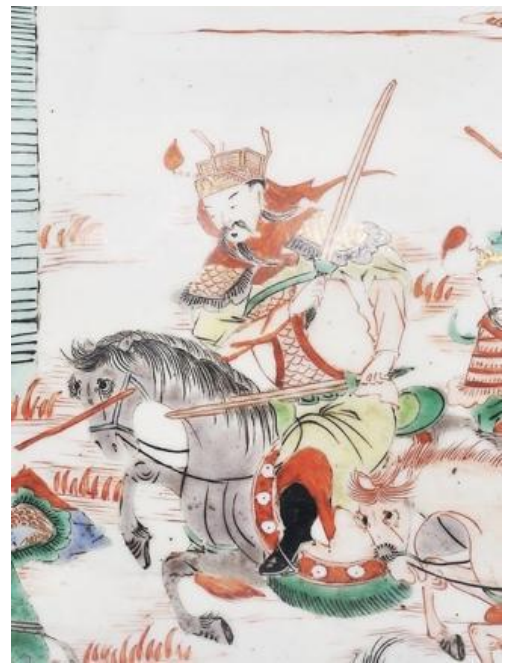

Figure 12 (Qing Dynasty) A five-color hatcovered jar 'Three Young Men Battling Against Lv Bu' in Kangxi Regime (partial), 45th, Fourth Season, Guardian, 2016.
4. In the first year of Jiajing regime of Ming Dynasty (1522), the Romance of The Three Kingdoms, vol. 1, "being sworn brothers", photocopy of People's Literature Publishing House, 1975. 


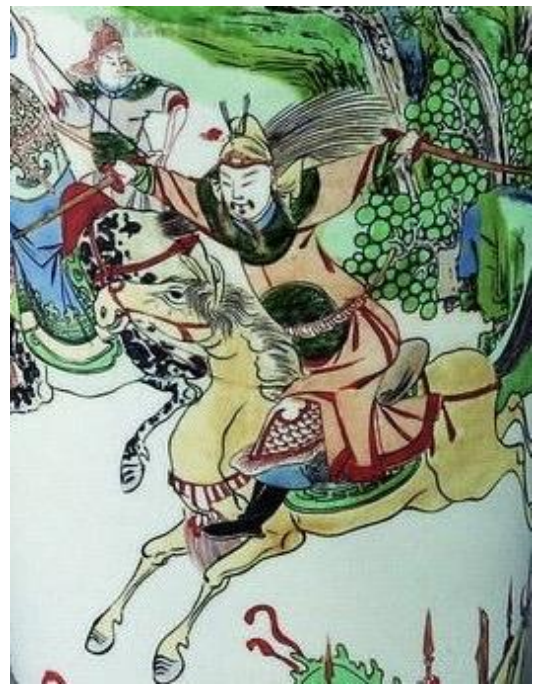

Figure 13 (Qing Dynasty) A five-color vase 'Three Young Men Battling Against Lv Bu' in Kangxi Regime (partial), Guardian, Spring 2003.

Zhang Fei has always been praised for his powerful image as a General. It was described in the "Romance of the Three Kingdoms" that "he was eight feet long, with a leopard-shaped head and ringed eyes, tiger-style beard, a voice like a giant thunderbolt." 5 "Zhang Yide, a man of Yan state, held a spear, and his eyes were round." ${ }^{6}$ [2] According to 'Three Young Men Battling Against $\mathrm{Lv} \mathrm{Bu}^{\prime}$, it can be seen that Zhang Fei ride on a piebald horse, his body leaning forward and lying on horse back, holding his spears in his hands; his eyes are big, his facial expression is fierce and courageous; his head is covered with a turban. ("Figure 14", "Figure 15", and "Figure 16")

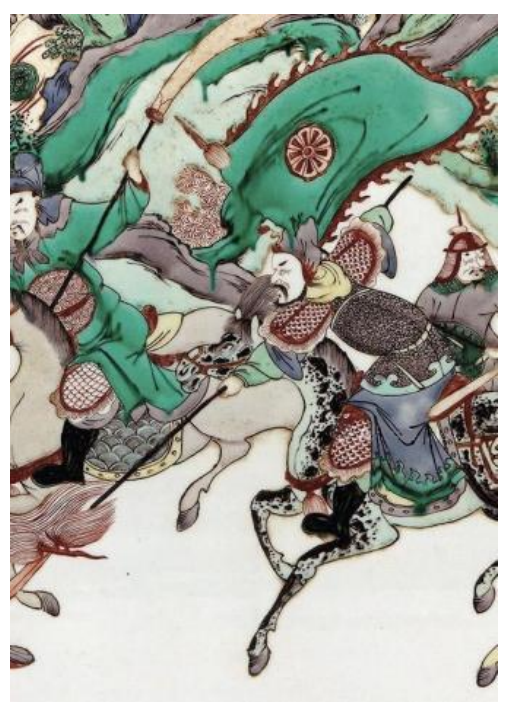

Figure 14 (Qing Dynasty) A five-color handicap 'Three Young Men Battling Against Lv $\mathrm{Bu}$ ' in Kangxi Regime (partial), Beijing, Spring 2016.

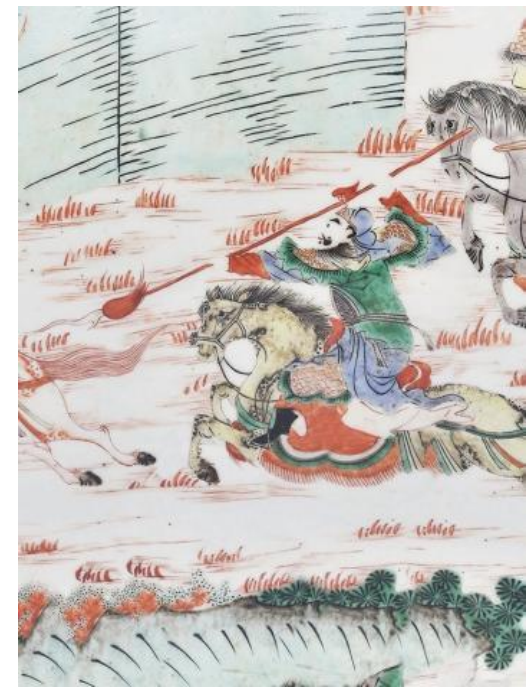

Figure 15 (Qing Dynasty) A five-color hatcovered jar 'Three Young Men Battling Against Lv Bu' in Kangxi Regime (partial), 45th, Fourth Season, Guardian, 2016.
5. In the first year of Jiajing regime of Ming Dynasty (1522), the Romance of The Three Kingdoms, vol. 1, "being sworn brothers", photocopy of People's Literature Publishing House, 1975.

6. In the first year of Jiajing regime of Ming Dynasty (1522), the Romance of The Three Kingdoms, vol. 1, "three battles against Lv Bu at Hulaoguan", photocopy of People's Literature Publishing House, 1975. 


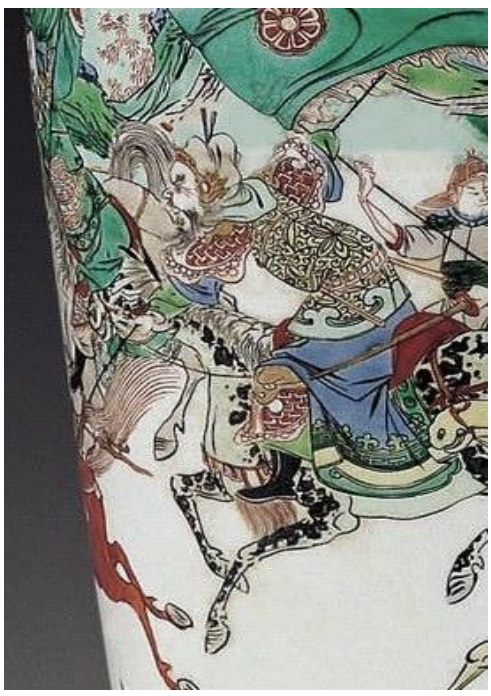

Figure 16 (Qing Dynasty) A five-color vase 'Three Young Men Battling Against Lv Bu' in Kangxi Regime (partial), Guardian, Spring 2003.

\subsection{The Design of the Scenic Elements of 'Three Young Men Battling Against Lv $B u^{\prime}$ in Kangxi Regime}

According to 'Three Young Men Battling Against $\mathrm{Lv} \mathrm{Bu}^{\prime}$ in Kangxi Regime, in addition to the four figures depicted, other elements of the scene, such as soldiers, rocks, flowers and trees, pass, flags, tents and clouds, are also depicted to heighten the tension of the battle.

As can be seen in the figure below, the background elements of the scene include layers of rocks and hills from far away, with crisp, condensed lines, mostly painted in archaic light green and archaic green, reflecting the sense of space and dislocation of the scene through the meandering and undulating changes in the hills and rocks. There is a pass with the word "Hulaoguan" written on it, depicting the place of battle, and the walls, which are made of brick and stone, are outlined in a single, neat line, with crisp and precise lines. There are military tents among rolling hills and rocks, where military affairs are discussed, mostly painted in antique yellow, with the upper part decorated with a circular pattern. In front of the rocks, there are various flowers and trees, interspersed with red and green, mostly in simple geometric combinations to form a dense and staggered landscape. Therefore, people can see the natural beauty of the natural landscape, and the picture would be richer. In addition to the main figure, there are six soldiers waving banners in the scene, vividly recreating the grand scene of the battle. Besides, the banners and trees of various colours are used to decorate the scene, which not only heightens the fierce atmosphere of 'Three Young Men Battling Against $\mathrm{Lv} \mathrm{Bu}^{\prime}$, but also completes the composition. [6] The clouds in the sky are also painted in alum red, with a strong, smooth, and delicate brushwork, forming a complete scene of the characters.("Figure 17", "Figure 18")

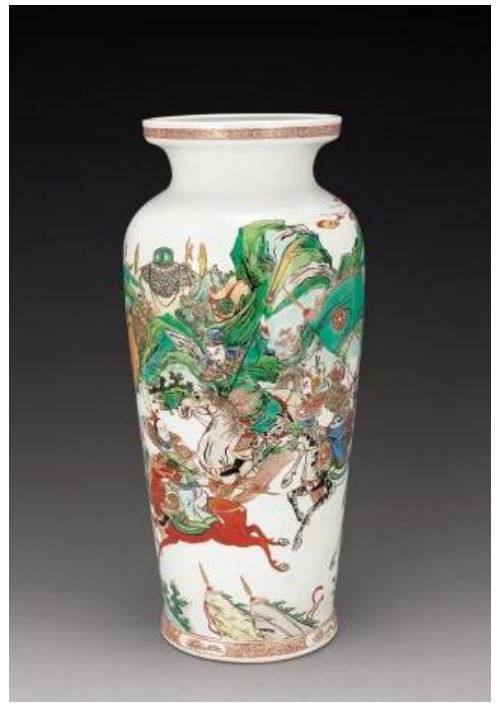

Figure 17 (Qing Dynasty) A five-color Pilgerflasche 'Three Young Men Battling Against Lv Bu' in Kangxi Regime (partial), 10th, Beijing Baoli.

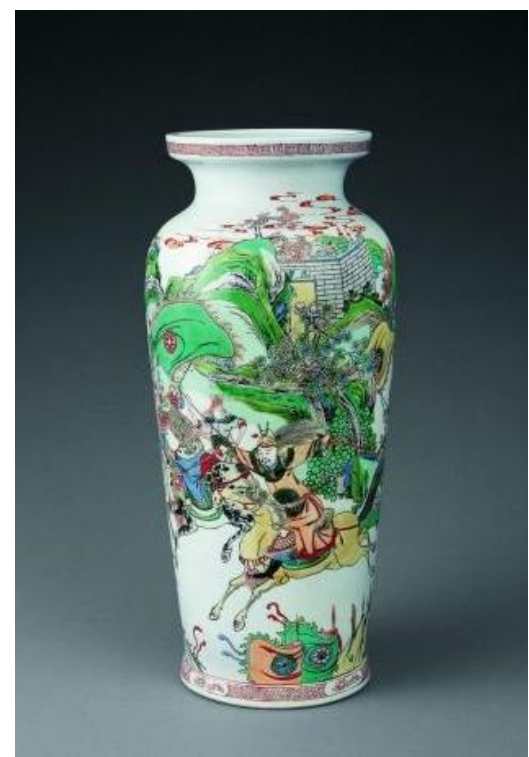

Figure 18 (Qing Dynasty) A five-color vase 'Three Young Men Battling Against Lv Bu' in Kangxi Regime, Guardian, Spring 2003. 


\subsection{Color Design of Five-color Porcelain 'Three Young Men Battling Against Lv $B u^{\prime}$ in Kangxi Regime}

In the colorful color expression of five-color porcelain in Kangxi Regime, the main colors are bright and strong red, green, yellow and blue, interspersed with purple, ochre and black, so that the theme of the picture is prominent, and the overall color is rich but not messy. [4] Five-color porcelain in Kangxi Regime uses single line, and is filled with special material. With the processing, glass blocks are formed, with bright and crystal colors.

In the bottle of 'Three Young Men Battling Against Lv Bu', it is mostly matched with red and green to highlight the main character. For example, the color of Lv Bu's clothes is a combination of red and green in a large area, with strong contrast, which not only meets the needs of folk aesthetics, but also gives people a strong visual impact. Acording to the color setting rules, it mostly uses different color setting according to different objects, so as to show the different texture of each object. For mountains, stones, flowers, trees and clouds, people often use different colors to express their respective characteristics and texture, which not only enriches the picture, but also is full of decoration. In addition, the five colors also follow the color setting law of "one body and several colors", that is, an object image is expressed in multiple colors. For example, the mountains and rocks are decorated with ancient green and light green, which not only increases the change and contrast of colors, but also strengthens the structural turning of the object and increases the sense of hierarchy of the object. The overall color of five-color porcelain in Kangxi Regime is simple, strong, bright and eye-catching, giving people a bold and unrestrained visual feeling.

\section{CONCLUSION}

The image of 'Three Young Men Battling Against Lv Bu' originated from painting. And the illustrations in the middle and late Ming Dynasty had a great impact on the establishment of the image program of five-color porcelain 'Three Young Men Battling Against Lv Bu' in Kangxi Regime. The five-color porcelain 'Three Young Men Battling Against Lv Bu' in Kangxi Regime has made further breakthroughs in pattern design, expression form and color application. Combined with the unique artistic characteristics of porcelain, the classical novel culture is expressed in new forms, which not only meets people's cultural needs, but also inherits and promotes the cultural spirits of the Three Kingdoms. And the essence of Traditional Chinese culture and the wisdom of Chinese civilization are the essences of being the person, the root of doing things and the way to govern the world.

\section{AUTHORS' CONTRIBUTIONS}

This paper is independently completed by Xiaomeng Chi.

\section{REFERENCES}

[1] Luo Guanzhong. Romance of the Three Kingdoms [M]. Shanghai: Shanghai Ancient Books Publishing House. 1980. (in Chinese)

[2] The Romance of The Three Kingdoms, Renwu Year during Jiaying period in Ming Dynasty, photocopy of People's Literature Publishing House, 1975.

[3] Zhang Yumei, Zhang Zhuping. The illustration flows of "Romance of the Three Kingdoms" in Ming Dynasty [J]. Journal of Huaihai University of Technology. 2011.(09). (in Chinese)

[4] Liu Lejun. An exploration of the antique porcelain "knife-horse-man" pattern in Kangxi regime [J]. Art Review. 2009.(12). (in Chinese)

[5] Zhu Xiangming. A study on the relationship between the text and illustrations of "Three Kingdoms" in the Ming and Qing dynasties [D]. Nanjing University. 2014. (in Chinese)

[6] Chen Ling. A study of five-color "swordhorse-man" in Kangxi regime [D]. Jingdezhen Ceramics Institute. 2013. (in Chinese) 